\title{
SONO E BEM ESTAR DO IDOSO DURANTE O PERÍODO DE QUARENTENA
}

Estherfanny da Nóbrega Pinheiro; Universidade do Estado do Pará; estherfanny.pinheiro@aluno.uepa.br

Giovana Silva Correa Reis; Universidade do Estado do Pará; giovana.reis@aluno.uepa.br

Lorena Garcia da Fonseca; Universidade do Estado do Pará; Iorena.fonseca@aluno.uepa.br Jéssika Sayuri Campelo Kato; Universidade do Estado do Pará; jessica.kato@aluno.uepa.br

Rebeca Andrade Ferraz; Universidade do Estado do Pará; rebeca.ferraz@aluno.uepa.br Camila Arcoverde de Oliveira; Grupo Cynthia Charone; nep@hospitalcynthiacharone.com

Brenda Gomes; Grupo Cynthia Charone; nep@hospitalcynthiacharone.com Cynthia Cyllene de Oliveira Charone; Grupo Cynthia Charone; cynthiacharone@yahoo.com.br

\section{RESUMO}

Introdução: O isolamento social durante a pandemia provocada pelo novo coronavírus afetou o bem-estar, principalmente, dos mais vulneráveis como os idosos. Nesta população, foram relatadas ansiedade, depressão, má qualidade do sono, inatividade física, entre outros durante o período de isolamento. Assim, faz-se necessário estudos sobre esses aspectos para melhorar os possíveis danos individuais e oferecer o suporte necessário. Objetivo: Avaliar o sono e o bem-estar psicológico de idosos durante a pandemia de COVID-19. Método: Estudo transversal e descritivo, com 799 pacientes avaliados mediante telemonitoramento. Foram incluídos idosos participantes do serviço de geriatria e gerontologia de um centro de referência em envelhecimento saudável Grupo Cynthia Charone e que aceitaram participar, mediante assinatura do estudo e aprovação no CEP. Resultados: Dos pacientes analisados, em relação à qualidade de sono, 506 declaram dormir bem frequentemente (66,3\%), 156 às vezes (20,4\%), e 101 quase nunca ou nunca dormem bem $(13,2 \%)$; sobre bem estar ao acordar, 703 pacientes responderam e $81,7 \%$ se sentem bem descansados e $15,6 \%$, pouco descansados. 754 pacientes relataram excesso de preocupação e ansiedade e $68 \%$ dos pacientes refere não apresentar tais sentimentos, $17,5 \%$ sente semanalmente e $14,5 \%$ sente quase todos os dias ou todos os dias. Por fim, dos 722 que relataram o nível de estresse, nenhum paciente se considera sem nenhum estresse. Conclusão: Apesar de não ser a maioria dos analisados, uma considerável parcela de idosos apresentou alterações no sono e no bem-estar psicológico, especialmente em decorrência da pandemia de COVID-19.

Palavras-chave: Saúde do Idoso; Isolamento Social. 